\title{
Income Inequality and Global Political Polarization: The Economic Origin of Political Polarization in the World
}

\author{
Yanfeng $\mathrm{Gu}^{1} \cdot$ Zhongyuan Wang $^{1}$
}

Accepted: 23 October 2021 / Published online: 23 November 2021

(c) Journal of Chinese Political Science/Association of Chinese Political Studies 2021

\begin{abstract}
Both income inequality and political polarization have increased dramatically in much of the world over the past few decades. One might wonder how these two phenomena correlate with each other. Are there any striking similarities in the correlated patterns of income inequality and polarization across the globe? More importantly, how can improved equality in income distribution contribute to mitigate political polarization? Although the potential polarizing effects of income inequality is a growing concern, the evidence provided by the existing literature, however, has been mixed and incomplete. This research seeks to address the shortcomings of the current scholarship by using the repeated cross-sectional data from six waves of the World Values Survey from 1990 to 2020, to investigate whether and how widened income inequality and growing political polarization are linked globally. The findings indicate that there is a positive and statistically significant cross-country association between levels of income inequality and political polarization. The results remain robust to different specifications. This research has the potential for advancing the study of linkages between income inequality and its political consequences.
\end{abstract}

Keywords income inequality $\cdot$ political polarization $\cdot$ political attitude $\cdot$ populism

\section{Introduction}

Some positive signs toward the goal of poverty reduction can be gleaned in the last three decades. Tens and millions of acutely poor people have escaped the poverty trap. However, despite the increase in the size of the economic pie, it is often divided unevenly across individuals, undermining inclusivity in development. Moreover, fragile states, unresolved conflicts, and trade wars in recent years have further complicated the task to build a more inclusive and sustainable society. Vulnerable populations are particularly at risk of suffering from relative economic deprivation. Most

Zhongyuan Wang

wangzy@fudan.edu.cn

1 Fudan Institute for Advanced Study in Social Sciences, Shanghai, China 
recently, the COVID-19 pandemic has further deepened income inequality by disproportionally impacting the world's already-poor ${ }^{1}$. Consequently, greater economic inequality presents a big threat to human development, as well as causes social, economic and political instability in both underdeveloped and developed countries.

The Sustainable Development Goals articulated by the United Nations in 2015 represent a universal call to "reduce inequality within and among countries", in which the target 10.1 is set to "reduce income inequalities". Income inequality, which refers to the extent to which economic output is unevenly distributed among the population [28], has increased in nearly all regions in the world since the turn of the century. ${ }^{2}$ This global trend has not only triggered heated debates about its underlying causes, but also spurred research into its far-reaching political implications. In the scholarly literature, income inequality has long been considered a social-economic problem that is associated with a variety of adverse outcomes. Rising income inequality is viewed as harmful to economic growth and sustainable development $[9,40,41]$. For example, unequal income distribution could result in higher crime rates and even motivate terrorist acts [1, 20]. Greater income inequality has also been found to be closely related to aggravated health condition, limited access to education, continued social discrimination, growing discontent among the working classes, as well as engendering anti-globalization sentiment $[8,13]$.

Income inequality has been typically examined from an economic perspective. However, it becomes more and more politicized in recent decades, causing a wide range of detrimental political consequences. Growing inequality could undermine social mobility, induce violent conflicts, and generate political tensions. At the same time, there is widespread concern that the "vicious cycle of poverty" and rising income inequality constitute an important cause of political polarization that threatens to divide and even destabilize a nation [3, 46, 47]. Political polarization refers to the vast and growing gap of political attitudes and identities among the public that undermine the pursuit of a common good. Its emergence is often compounded by the rise of ideologically divided masses and radical political parties. In recent decades, political polarization has intensified globally and has been a disruptive force in societies across the world, from advanced countries including the US and those in Europe to the developing world such as Brazil, India, Turkey and Poland. To examine the driving forces behind political polarization, the current well-developed scholarship has mainly examined factors such as the changes in socio-demographic cleavages, the suffering of economic hardship, the rise of identity politics, the design of political institutions, and the essential role of social media in shaping people's ideologies [21, 25, 46]. Meanwhile, these studies typically focus on a single country (for example, the US) or a region (for example, Europe) and have so far neglected to identify a global causal pattern of political polarization [19, 38]. Therefore, this research will contribute to the scholarly literature by considering the role of income

\footnotetext{
1 See https://www.worldbank.org/en/news/press-release/2020/10/07/covid-19-to-add-as-many-as-150million-extreme-poor-by-2021 (accessed December 27, 2020).

2 See World Inequality Report 2018, available at https://wir2018.wid.world/files/download/wir2018-fullreport-english.pdf (accessed June 8, 2021).
} 
distribution with more comprehensive measures, as well as generalizing the correlation between income inequality and political polarization across the globe.

These are the 3 key questions underpinning this paper: how are income inequality and political polarization related to each other? Are there any telling similarities in the correlated patterns of income inequality and polarization across the globe? What will be the role played by improved equality in income distribution in mitigating political polarization? This research, using the repeated cross-sectional data from six waves of the World Values Survey from 1990 to 2020, investigates whether and how widened income inequality and growing political polarization are linked across different countries. The country-level analysis shows significantly positive correlation between income inequality and attitude polarization (measured by the dispersion of attitude toward equality, ownership, government, competition, democracy, as well as social justice). The results remain robust to different specifications when adopting alternative measures of income inequality and introducing additional control variables. Following this logic, we expect to see that at the individual level, the impact of income inequality on attitudes toward the six issues will be significantly different among different societal-political groups. To test this hypothesis, we divide individual respondents into different groups along three dimensions (income groups, social class, and employment status) and test the magnitude of the influence of the Gini coefficient on each of these groups. The analysis confirms this hypothesis that income inequality (measured by Gini coefficient) has a heterogeneous effect for different groups of individuals, which may explain the positive relationship between income inequality and the dispersion of attitude at the country level.

The remainder of this article is organized in the following sections. In Section 2, we first offer a review of the relevant scholarship that this research inquiry is located within, and highlight our contribution. We then clarify about our data and measurement strategies in Section 3 and provide some preliminary evidence on the connection between income inequality and political polarization. Our main empirical results are presented and discussed in Section 4. Section 5 concludes with some potential policy implications and directions for future research.

\section{Connecting Income Inequality and Political Polarization}

The simultaneous presence of rising income inequality and flourishing political polarization has led scholars to hypothesize that these two major challenges could be causally linked [10, 19, 42, 47]. However, to date, there has been little agreement on whether income inequality has a significant effect on polarization. While the scholarship has burgeoned with efforts to offer empirical evidence on the connection between income inequality and political polarization at both the mass and elite levels, such a strand of literature usually focuses on electoral politics and party politics in liberal democratic regimes. Scholars consider whether political attitudes (e.g., specific policy attitudes) or political behavior (e.g., roll-call behavior) differ for members of major political parties and whether the median position of party members has moved farther apart across time as a function of income inequality. In the seminal book "Polarized America", McCarty et al. [38] demonstrated that both 
political and economic polarization have been on the rise in the United States since the 1970s, and the widening of political and ideological divisions among American citizens has been closely related to the rise in wealth disparity, with the two interacting like "a dance of give and take and back and forth causality". Echoing the argument made by MaCarty and his colleagues, Garand [24] used state-level evidence and data on U.S. senators' roll-call behavior to evince that the same process applies to the American state electorates and their elected representatives. Using more recent data on polarization in U.S. state legislatures and state-level income inequality, Voorheis et al. [48] concluded that "income inequality has a large, positive and statistically significant effect on political polarization" in American politics. This is what caused state Democratic parties to become more liberal and replaced moderate Democratic legislators with Republicans. A similar pattern has also been identified in Europe. Relying on aggregated household survey data for 25 European countries from 2002 to 2014, Winkler [49] suggested that increasing inequality on average leads to a rise in the probability of an individual supporting extreme left-wing parties as well as more support for far-right parties among older citizens.

The above arguments are not completely new if one considers the much broader scholarship on economic voting. Pocketbook economic concerns have generally been accepted as one of the determinants and key predictors of electoral outcomes [33]. "It's the economy, stupid" ${ }^{3}$ is a widely-used phrase in election campaign messages and media reports that emphasize the electoral role of various economic factors such as unemployment rates, income inequality, and economic insecurity. These conventional studies suggest that an increase in income inequality tends to translate into greater support for left-wing political parties of the working class as they advocate more radical welfare policies [29, 43]. In recent years, with the re-emergence of populist movements and the surge in support for far-right forces in many parts of the world, there has been renewed interest in economic explanations and growing recognition of the links between income inequality and radical voting. For instance, Jesuit et al. [31] found that social capital (operationalized as income inequality) played a major role in mediating the relationships between immigration, unemployment, and electoral support for extreme right-wing parties in western Europe. Becker et al. [11] conducted a district-level analysis which identified that it was low income and high unemployment rate instead of voters' exposure to the EU that determined the Brexit referendum vote, and such a voting pattern also took place in the 2017 French presidential election. Furthermore, B'o et al. [7] utilized Sweden's election data and found that the groups experiencing lower relative income and higher job insecurity tend to support the radical right (Sweden Democrats) electorally. Similarly, the recent work by Dorn et al. [18] suggested that an increase in economic deprivation has a pronounced effect on the support for radical right and left-wing parties in Germany, where "the greater the prevalence of relative poverty, the greater the success of nationalistic parties at the polls". Related studies also examine how economic crisis and trade shocks

\footnotetext{
3 Julian Zelizer, "'It's the economy, stupid' all over again”, available at: https://www.cnn.com/2020/05/ 08/opinions/economy-2020-election-trump-biden-zelizer/index.html. (Accessed Feburary 12, 2021)
} 
may help reshape domestic income distribution and unemployment rate that further exacerbate political polarization [6, 23, 37]. As Colantone and Stanig [15] argued, "losers" of globalization in Western Europe are more likely to vote for political parties at the two extremes of the ideological spectrum, and therefore "globalization might not be sustainable in the long run if the welfare gains that trade brings are not equally shared within society" (p.951).

There are four plausible mechanisms identified in the literature that can explain the causal relation between inequality and polarization. First, income inequality will create unfavorable comparison with other members of society, creating a tangible sense of who wins and loses in society, thus incurring a stronger sentiment of "relative deprivation" [44]. The perceptions of poverty, deprivation and injustice are considered to arouse subjective feelings of frustration and anxiety that ultimately can result in more extreme political attitudes and ideologies [4]. Second, under conditions of growing poverty and greater inequality, different sub-groups of the population tend to adopt risk-averse and in-group favoring strategies while reducing out-group interactions [46]. This will facilitate the formation of the concept of "distinction", which may first push the subpopulation facing economic hardship to become polarized and then, more detrimentally result in the whole population being susceptible to a state of polarization [23]. Third, greater income inequality can amplify class identity and awareness in societies. People with a high level of income inequality are more likely to distinguish themselves and make decisions based on economic cleavages. Meanwhile, radical parties and populist politicians could capitalize on this and seek power by appealing to voters' needs and mobilizing supporters along class lines [5]. This may intensify resentment against the political mainstream and make it increasingly difficult to achieve political consensus. Fourth, unequal income distribution could impact political polarization by causing the size of the middle class to shrink. A large and vibrant middle class has been considered extremely important to maintaining social harmony and political stability. Rising inequality reduces the share of income going to middle-class families and relegates many middle-class families to a lower-income status. The lack of a middle-class buffer zone will lead to a surge in angry politics and the rise of polarized ideologies [22].

While the above studies seem to have provided compelling evidence for the connection between income inequality and political polarization, the debate regarding the polarizing impact of income disparity still prevails. For instance, Dettrey and Campbell [16], by examining individual-level data from 1972 to 2008, argued that the increased ideological polarization in the U.S. was mainly driven by political partisanship rather than the result of growing income inequality. Bosancianu [12] tested this theory by using European data and also found no significant effect of income inequality on attitude polarization if educational inequality is controlled for. Similarly, in his recent book The Great Alignment, Abramowitz [2] highlighted that today's political polarization is unique in modern U.S. history and mainly arose out of "negative partisanship" rather than any other factors such as economic discontent. Similarly, Mutz [39] analyzed panel data from 2012 to 2015 and found that individual economic hardship had little impact on candidate preference and Donald $\mathrm{J}$. Trump's victory in the 2016 election was mainly attributed to group status concerns. 
In spite of a plausibly posited positive linkage between income inequality and political polarization, the current empirical findings are far from conclusive, calling for a more comprehensive and nuanced survey of the relationship. Moreover, these studies mostly focus on party polarization and radical voting behavior in Western democracies and have not fully explored the global impact of income inequality on the polarization of political attitudes in various countries. This research builds on the existing literature and uses cross-country data from six waves of the World Values Survey (WVS) from 1990 to 2020 to re-examine the polarizing effect of income inequality globally. Our paper may contribute to the scholarship in several ways. First, while there are exceptions, most existing studies have involved individual country or regional analyses. Thus, these findings suffer from a lack of generalization since they may not be valid for other places in the world. By utilizing the large number of observations in WVS to test the plausible connection globally, we are able to cover both developed and developing countries. This research will then help to identify a more generalizable linkage pattern between income inequality and polarization. Second, we use 6 waves of WVS from 1990 to 2020 to test the hypothesis. The large dataset allows us to control for country and year fixed effects as well as a number of other variables that may correlate with both income inequality and political polarization. The aggregated country-level analysis combined with an individual-level test is designed to treat political polarization as both a state and a process, a strategy to provide a more comprehensive understanding of the phenomenon. Third, we adopt different operationalization strategies to measure the key variables. Income inequality is measured not only in the conventional way using the Gini index, but also by the 20:20 ratio (how much richer the top 20\% of populations are relative to the bottom $20 \%$ ) and Palma ratio (the ratio of the richest $10 \%$ of the population's share of gross national income divided by the poorest 40\%'s share). These different income inequality metrics will help generate more robust results. To measure political polarization, we use the standard deviation of four attitude indicators, which extends the narrow definition of polarization as voting choice to the divergence of political attitudes on a broad range of issues.

\section{Variable and Data}

\section{Measuring political polarization}

Fundamentally, polarization refers to "movement away from the center toward the extremes" [21]. Political polarization often comes in form of elite/party polarization and mass polarization. There is an extensive literature on American elite polarization which focuses on rising partisan differences in roll-call voting behavior in the Congress [14, 32, 38]. The party-based roll-call measurement of polarization does have some merits, but it cannot be used for other countries that have different political systems. In order to compare the level of polarization globally, our research concentrates on political polarization of the mass public. Traditionally, mass polarization is often measured according to radical voting choice (vote share for radical politicians and parties). However, voting behavior data can be inadequate because 
people make their electoral choice not simply based on their own preferences, but rather by comparing different candidates [21]. This means that a strategic decision (so-called "strategic voting") is made rather than a radical vote reflecting polarization. Therefore, in order to measure mass polarization more directly and accurately, we examine the polarization of ideological positions that individuals hold and where they stand on specific political values. Such a measurement allows us to identify both the level of mass polarization and the trend in mass polarization, as well as make cross- $\mathrm{N}$ analysis possible.

Our measurement of mass polarization is based on responses to related multiple-choice questions from the World Values Survey from 1990 to 2020. The WVS is a cross-national project that was administered in waves (five years per wave) to explore people's changing attitudes, values and beliefs on a wide range of social and political issues. It uses a common questionnaire with the variables of interest relevant to this research and covers about 100 countries of varying income levels and political systems. We focus on the most recent 6 waves $^{4}$ and include countries with available data. Consistent with the work of Lindqvist and Ostling [35], we first choose four questions that ask respondents about how they locate their views on different economic aspects of left and right on a 1-to-10 scale ${ }^{5}$. The four selected questions and their measurement details are as follows: (1) economic differences VS. economic equality: 1 indicates "We need larger income differences as incentives" and 10 means "Incomes should be made more equal"; (2) private ownership VS. state ownership: 1 indicates "Private ownership of business should be increased" and 10 means "Government ownership of business should be increased"; (3) People responsibility VS. Government responsibility: 1 indicates "People should take more responsibility to provide for themselves" and 10 means "The government should take more responsibility to ensure that everyone is provided for"; (4) Competition VS. No Competition: 1 indicates "Competition is good. It stimulates people to work hard and develop new ideas" and 10 means "Competition is harmful. It brings out the worst in people." We tried to conduct a factor analysis of the four items to see whether they will load on a single factor. However, the results show that the KaiserMeyer-Olkin (KMO) test has values less than 0.7 (only at 0.442 ). Therefore, it will be more appropriate to take them as four separate dimensions.

In addition to the above four survey items centering on economic ideologies, this research advances the measurement of polarization by also considering people's political attitudes toward democracy and social justice. As for attitudes toward democracy, we include seven survey items ranging from free elections to religious authorities (see Table 1). For each item, 0 stands for "Against democracy" whereas 10 represents "An essential characteristic of democracy". The results of performing factor analysis on the seven items show that there is one common factor that accounts for $56.7 \%$ of the variance. The KMO measure

\footnotetext{
${ }^{4}$ We exclude the first wave from 1981-1984 because the data was largely limited to developed countries.

5 According to Lindqvist and Ostling [35], focusing on these four questions will strike a balance between the measurement accuracy and the useful number of observations. A comparison between the results for the four different measurements will also provide a robustness check on the estimates.
} 
Table 1 Factor analysis of political attitudes toward democracy

\begin{tabular}{ll}
\hline Items & Factor loadings \\
\hline People choose their leaders in free elections & 0.6813 \\
Civil rights protect people's liberty against oppression & 0.6612 \\
People receive state aid for unemployment & 0.5998 \\
Women have the same rights as men & 0.5529 \\
Governments tax the rich and subsidize the poor & 0.4764 \\
The army takes over when government is incompetent & 0.1474 \\
Religious authorities interpret the laws & 0.1217
\end{tabular}

Table 2 Factor analysis of political attitudes toward social justice

\begin{tabular}{ll}
\hline Items & Factor loadings \\
\hline Homosexuality & 0.6873 \\
Prostitution & 0.7403 \\
Abortion & 0.7162 \\
Divorce & 0.8779 \\
Euthanasia & 0.5967 \\
Suicide & 0.5489 \\
\hline
\end{tabular}

(0.725) and the Bartlett test of sphericity $(p<0.001)$ together indicate that the factor analysis is well above the acceptable limit. Table 1 illustrates the factor loadings after rotation for the one-factor solution. As for attitudes toward social justice, six items ranging from the attitude toward homosexuality to suicide are included. For each item, 0 stands for "Never justifiable" whereas 10 represents "Always justifiable". Similarly, the results of factor analysis suggest that there is one common factor that explains $77 \%$ of the total variance. The KMO measure $(0.861)$ and the Bartlett test of sphericity $(p<0.001)$ together verified the factor analysis. The factor loadings after rotation for the one-factor solution are presented in Table 2.

Based on the factor analyses, we finally create six attitude variables, among which four represent the economic dimension, one on the democratic dimension, and another on the societal dimension. We use the standard deviation of each of the six variables to measure the level of mass polarization, namely, the six outcome variables. Standard deviation is a commonly-used statistic that represents the "dispersion" of a set of values relative to its mean. It provides a simple and transparent measurement of attitude polarization which can be understood as "movement away from the center toward the extremes". It is reasonable to consider that the larger the value of the standard deviation, the higher the level of political polarization. Using repeated survey data spanning 30 years allows us to measure the long-term development of polarization along the economic, democratic and societal lines, as well as better explore the cross- $\mathrm{N}$ relationship between changes in income inequality and political polarization. 


\section{Measuring income inequality}

There are various metrics for the operationalization of income inequality [28]. The most popular measure is the Gini coefficient which is derived from the Lorenz curve. It ranges between 0 and 1 , where 0 indicates perfect equality and 1 represents perfect inequality. When conducting the country-level analysis, we use the country-year estimates of the Gini coefficient from the World Income Inequality Database (WIID) constructed by United Nations University World Institute for Development Economics Research(UNU-WIDER). The WIID provides a comprehensive set of crossnational data on income inequality with global coverage for long time periods. It is one of the most widely used sources of secondary data and statistics about income inequality in social science research [30]. The latest version of the WIID was newly released in May 2020, which can be matched with the updated mass polarization data.

The measurement of the Gini coefficient can be based on either consumption or income. Typically, there is a slight difference between the two. The WIID reports the Gini coefficient from different dimensions using consumption or income, but not all types of Gini coefficients are available for every country. In the WIID dataset, many countries only report the Gini coefficient of some types, using different data sources such as the World Bank, the OECD, the United Nations, Luxembourg Income Study, etc. This research therefore selects four types of Gini coefficient with high quality from the WIID, namely Gini coefficient of equivalized net income, Gini coefficient of net income per capita, Gini coefficient of equivalized consumption, and Gini coefficient of consumption per capita (two use income and the other two use consumption). When we use any one of these four Gini coefficients to match the WVS data, the country-level observations will drop from 269 to no more than 71. In order to solve the problem of small sample size, we calculate the mean value of these four Gini coefficients as the key independent variable. Appendix Table 7 reports the correlation matrix of these Gini coefficients, which shows that the four types of Gini coefficients are highly correlated with their mean value.

However, the Gini index alone is not entirely satisfactory (for example, the Gini coefficient can decrease while the number of poor people increases) ${ }^{6}$. Therefore, for the country-level analysis, we introduce two additional measures of income inequality to check the robustness of the results. One is the "20/20 ratio" which compares the average income of the top 20\% richest to the bottom 20\%. The other is the Palma ratio which refers to the national income share received by the top $10 \%$ over that of the bottom $40 \%^{7}$. These two alternative metrics exemplify distributional politics as the struggle between the rich and poor, which therefore could better represent economic polarization.

\footnotetext{
6 See related discussions in Sitthiyot and Holasut [45].

7 The target 10.1 of the Sustainable Development Goal of United Nations is to "sustain income growth of the bottom 40 per cent of the population at a rate higher than the national average".
} 
Table 3 Descriptive statistics

\begin{tabular}{llll}
\hline Variable & Obs & Mean & Std. Dev. \\
\hline Std of attitude to equality & 147 & 2.783 & 0.361 \\
Std of attitude to ownership & 142 & 2.669 & 0.417 \\
Std of attitude to government & 147 & 2.787 & 0.353 \\
Std of attitude to competition & 144 & 2.452 & 0.370 \\
Std of attitude to democracy & 80 & 0.744 & 0.137 \\
Std of attitude to social justice & 118 & 0.853 & 0.227 \\
Gini Coefficient & 150 & 0.380 & 0.091 \\
Top 20\% / bottom 20\% & 139 & 8.548 & 4.962 \\
Palma ratio (top 10\% / bottom 40\%) & 133 & 1.905 & 1.134 \\
Life expectancy at birth & 150 & 73.732 & 5.646 \\
GDP per capita (1000 USD) & 150 & 14.425 & 16.876 \\
Population (one million) & 150 & 92.398 & 221.586 \\
Deaths in conflicts & 150 & 1.601 & 2.598 \\
OECD country & 150 & 0.427 & 0.496 \\
\hline
\end{tabular}

\section{Control Variables}

To test the hypothesis postulating a relationship between income inequality and political polarization, we also include a number of controls that might correlate with both of the two key variables. For the country-level regression models, we control for the log of GDP per capita, the log of population, life expectancy at birth (as a proxy for the quality of governance), ${ }^{8}$ the OECD dummy, and the year dummy. Since the existing literature has also identified the relationship between conflicts, inequality and polarization (Esteban and Ray 2011), we also include conflicts (measured by the number of deaths in conflicts in a particular year) as a control variable using the data from Uppsala Conflict Data Program. More detailed descriptive information of the dependent variables, independent variables, and other control variables is respectively summarized in Table 3.

\section{Results}

In this section, we report and discuss the results of our regression analysis. We first report the results of the country-level models using the Gini coefficient as the measure of income inequality. We then perform robustness tests by introducing alternative measures of income inequality (20/20 ratio and Palma ratio) and controlling for additional variables (country-level response rate). In the following part, we focus on how citizens' different income levels influence their polarized attitudes. By integrating country-level analysis with individual-level test, this research aims to provide

\footnotetext{
${ }^{8}$ We obtained from the data on GDP, population, and life expectancy from the World Bank and the WIID.
} 

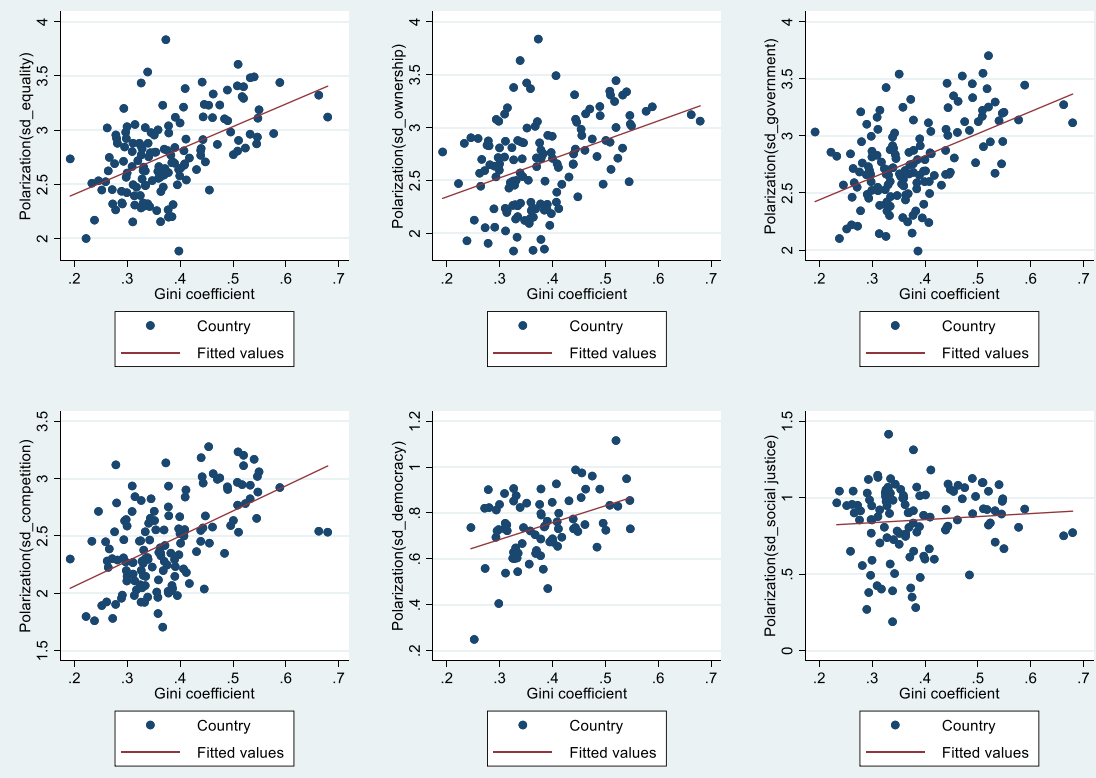

Fig. 1 Correlation between the Gini coefficient and the country-level attitude polarization

more concrete and comprehensive evidence for the relationship between income inequality and political polarization. Some results discussed here which are not included in the main body of this article, would be available in the Appendix.

As shown in Figure 1, the preliminary analysis using the pooled data across all the six survey cycles shows a positive correlation (significant with $p<0.01$ ) between the Gini coefficient and attitude polarization. Countries showing higher levels of income inequality measured by the Gini coefficient are associated with greater degrees of political polarization on the six issues (equality, ownership, government, competition, democracy, and social justice). In other words, countries with greater income inequality tend to be more polarized on economic, democratic, and societal ideologies. Such a notable pattern becomes even more significant if we exclude some outliers.

We further examine the relationship between income inequality and citizens' polarized attitudes towards all the six economic, democratic, and societal issues. Panel A of Table 4 reports the estimates using Gini coefficient as the measure of economic inequality. The results of this panel show that countries' income inequality (measured by Gini coefficient) is significantly related to citizens' polarized attitudes (measured by the standard deviation). The size of the significant levels holds up strongly when controlling log of GDP per capita, log of population, life expectancy at birth, deaths in conflicts, OECD dummy, year dummy and clustering robust standard errors to the country level. This means that the higher the level of income inequality in a country, the more serious the country's political polarization on relevant issues. 


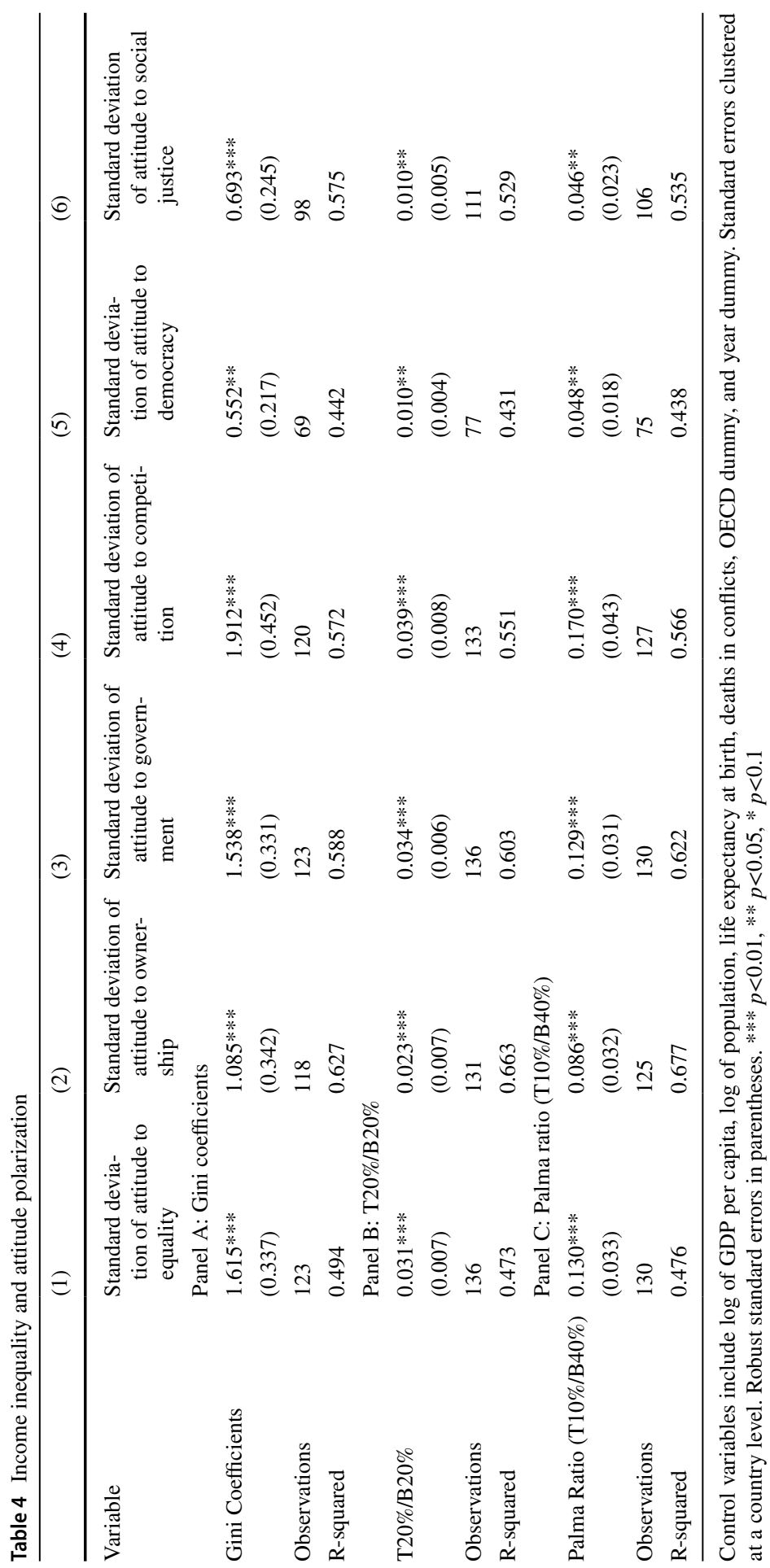


The association between economic inequality and political polarization is not only statistically significant but also economically meaningful. We find that a 0.1 increase in Gini coefficient will lead to a $4-8 \%$ increase in political polarization when different measures of political polarization are used. For instance, the statistically significant Gini coefficient in column 2 suggests that a 0.1 increase in the Gini coefficient will lead to a 0.1085 increase in the standard deviation of attitude to ownership, which is then translated into $4.06 \%(0.1085 / 2.669)$ when evaluated at the mean of the standard deviation of attitude to ownership. And similarly, the coefficient of Gini coefficient in column 6 suggests that a 0.1 increase in Gini coefficient will lead to a 0.0693 increase in the standard deviation of attitude to social justice, which is then translated into $8.12 \%(0.0693 / 0.853)$ when evaluated at the mean of the standard deviation of attitude to social justice.

In order to further check the robustness of our findings, we re-examine the relationship between economic inequality and political polarization by using two alternative measures of income inequality, the 20/20 ratio and the Palma ratio. These two measures are better at weighting observed income distributions and tend to be more sensitive to inequality at the extreme tails. As shown in Panels B and C of Table 4, our earlier results continue to hold.

One major concern is that, if the response rate is somewhat related to income inequality, it may cause our estimate to be biased. In the World Values Survey, the response rate on the items we have examined in this research varies cross countries. The overall country response rate has been very high, with the average response rate on the four indicators remaining somewhere between 94-98\%. However, the response rate of some countries in certain survey years is relatively low. For example, in 2007, the response rate of China to the question of ownership was only $65.8 \%$, which is the lowest in the world. To ensure that our results are robust, we re-examine the relationship between economic inequality and political polarization by further controlling for the country's response rate and find consistent results in Appendix Table 8. It is, then, apparent that the association between income inequality and political polarization identified in the survey data is not influenced by selfselection response bias.

Another concern is the use of the mean value which is derived from four different Gini measures that may not be comparable enough to represent an aggregation. Therefore, we reconducted the analysis only using the Gini coefficient based on income per capita. Panel A of Table 5 reconfirms the positive relationship between Gini coefficient and political polarization. Furthermore, we find that when using Gini coefficient based on income per capita as the measure of economic inequality, a 0.1 increase in Gini coefficient will lead to a $3.9-7.65 \%$ increase in political polarization, which is similar in magnitude to the previous findings. Besides, we also further control for the country's response rate for each issue, and find support for our earlier results (seen in Panel B in Table 5).

We have found that at the country level, income inequality increases the display of polarized attitude toward equality, ownership, government, competition, democracy as well as social justice. Following this logic, we expect to see that at the individual level, the impact of income inequality on attitudes toward the above issues of each income group will be significantly different, meaning that the Gini coefficient 


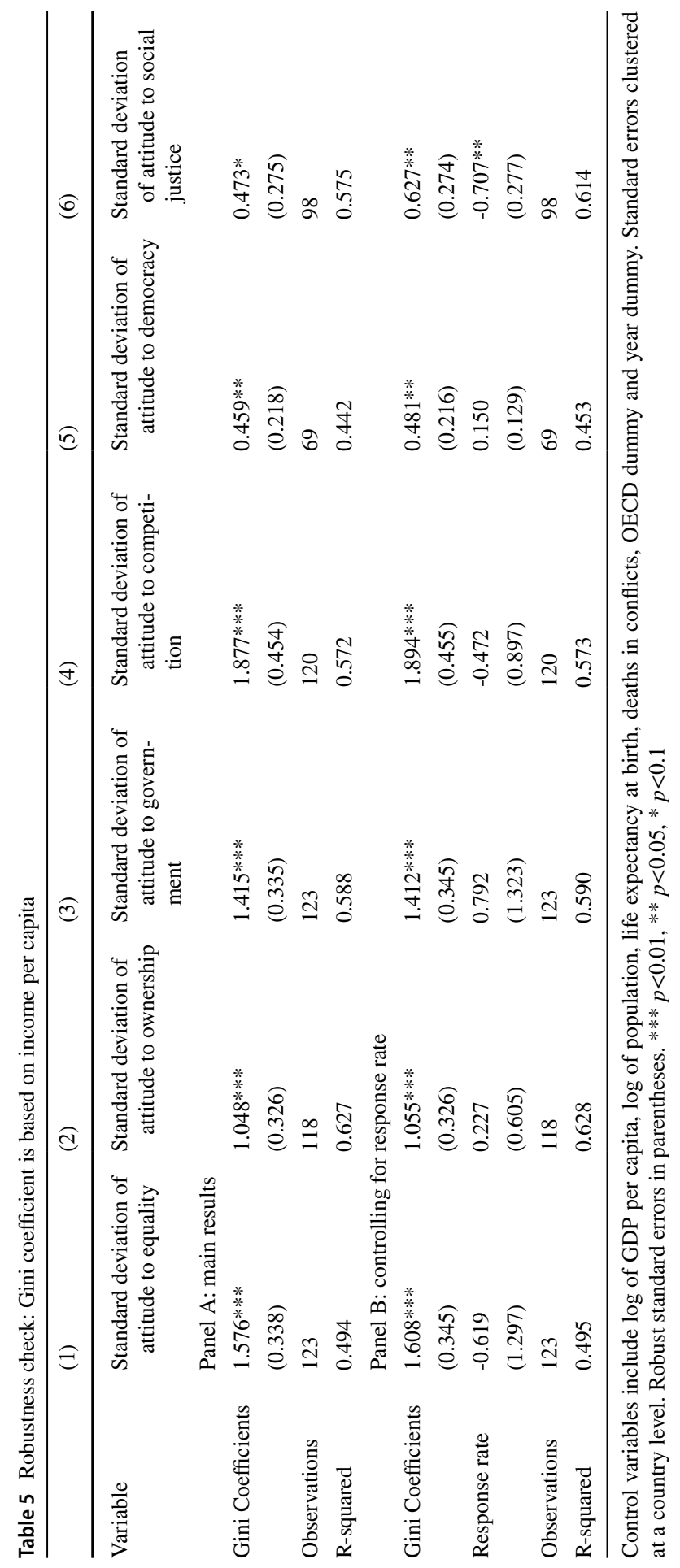


(income inequality) has a heterogeneous effect for different groups of individuals. To test this hypothesis, we divide our sample into different socio-political groups and test the magnitude of the influence of the Gini coefficient on each of these groups. The results will further reveal the mechanism, which explains how the increase of income inequality leads to the polarization at the country level.

We divide individuals into different groups along three dimensions which may correlate with respondents' economic status. First, we classify the respondents into low-income, lower-middle-income, middle-income, upper-middle-income, and high-income groups based on their self-reported income scale ${ }^{9}$. Second, we categorize the respondents into lower class, working class, lower middle class, and upper $\&$ upper middle class based on the social class indicators in the survey. Third, we divided the respondents into full time, self-employed, retired, housewife, and others based on their employment status. The dependent variable is individuals' attitude towards the six dimensions of economic, democratic and societal ideologies on a 1-to-10 scale. Table 6 highlights the regression results of the first classification method while the regression results for the second and third classification methods are included in the appendix.

We control for a set of demographic factors (age, gender, social class, marital status, and education level of the respondents), the fixed effects of country and year, as well as the town size where respondents live and the language respondents use, all of which may correlate with both income and attitude of respondents. Table 6 reports the main effects of the Gini coefficient and income group, showing that the Gini coefficient has a statistically significant impact on various attitudes (except for competition), and different income groups have significant differences in various attitudes. More importantly, if our conjecture that the impact of income inequality on attitudes toward the above issues of each income group will be significantly different is correct, at least one of the interactions should be significant. The results of Table 6 confirm our conjecture, which means that the effect of the Gini coefficient on the group is significantly different from that on the low-income group (the reference group). In other words, political cleavage can arise in response to economic inequality.

Furthermore, we use other dimensions to divide the sample into different groups to test the robustness of the results. First, we divide the sample into five groups based on social class, and then test our hypothesis by including the interaction between social class and the Gini coefficient in the regression model. The results reported in Appendix Table 9 show that at least one of the interactions in each column is statistically significant, suggesting that the Gini coefficient (income inequality) has a

\footnotetext{
9 The WVS does not provide a measure of actual income for the respondents and their families, so we use the respondents' self-reported income level (perceptions of their placement in one of ten income deciles) as a proxy variable for their actual income. In the WVS data set, the original 1-to-10 deciles of income scale refer to the income level of respondents' households relative to the whole country. More specifically, 1 indicates that the respondent thinks his/her household belongs to the highest income group in the country and 10 represents the lowest income group in the respondent's country. There is a concern that only the poorest and richest respondents may accurately place themselves into deciles. To address this problem, we reclassify the original 10 income deciles into 5 income groups to reduce the risk of misclassification, namely, Low-income group (scale 1-2), Lower-middle-income group (scale 3-4), Middleincome group (scale 5-6), Upper-middle-income group (scale 7-8), High-income group (scale 9-10).
} 


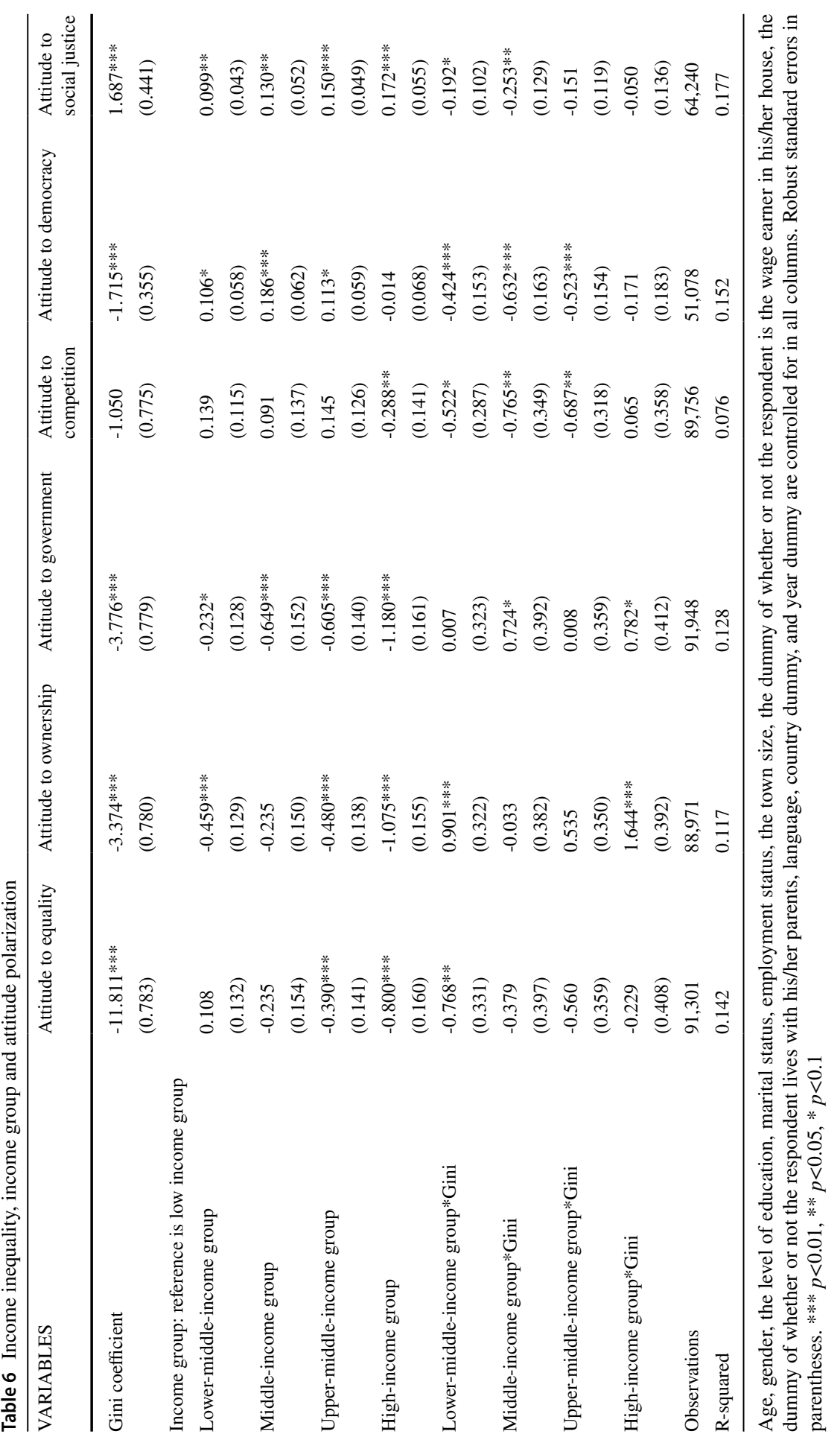


heterogeneous effect on different social class statuses. Second, we divide the sample into six groups based on the respondent's employment status, and test our conjecture by including its interaction with the Gini coefficient. The results reported in Appendix Table 10 show that at least one of the interactions in each column is statistically significant, corroborating our conjecture again. In short, the above results further confirm our hypothesis that the Gini coefficient (income inequality) has a heterogeneous effect on different groups of individuals. This suggests that an increase in income inequality will lead to the dispersions of attitude among individuals, which may explain why we can find in the state-level analysis that the influence of income inequality on standard deviation of attitude is statistically and positively significant.

So far, the analysis has provided empirical evidence that polarized sentiments among the masses are strongly associated with income inequality. Furthermore, the individual-level analysis implies that the heterogeneous effect of economic inequality on individuals' attitude may be the plausible mechanism through which the increase of inter-personal inequality leads to the polarization at the country level.

\section{Conclusion}

Given how the proliferation of income inequality and political polarization have increasingly garnered more importance, the existing studies provided mixed evidence in articulating the correlation between the two phenomena. Using six waves of the World Values Survey from 1990 to 2020, this article was able to test the connection between income inequality and political polarization globally. The baseline results chime with the general argument that the widening gap between the richest and poorest is closely tied to the emergence of polarization. The patterns maintain robust even to different specifications. Of course, such a strong positive correlation does not mean the two phenomena are necessarily causal. However, by combining the findings with an analysis of possible mechanisms in the literature, the results can be suggestive evidence about the polarizing effects of income inequality.

More importantly, our analysis can provide some insights into the economic origins of ongoing populist movements around the world. Whether in the developed or developing world, income inequality is growing rapidly and constitutes an important catalyst in driving political divisions. This underscores the importance of inclusive development strategies and redistributive policies aimed at ensuring a fair, povertyfree society and global justice [26, 27]. Successfully addressing the development problem not only requires reducing the number of people falling into absolute poverty $[34,52]$, but also needs to cope with the alarming challenges of relative economic deprivation and income inequality across the globe [36]. Otherwise, the result will be a range of detrimental political effects such as political polarization. Our research findings lend support to the utility of reducing the level of income inequality so as to fundamentally break the vicious circle of political polarization. Finally, one caveat to consider is that mass polarization is not only attitudinal but also behavioral. Hence, future research may consider other behavioral measures of political polarization in further assessing the impacts of income inequality. 


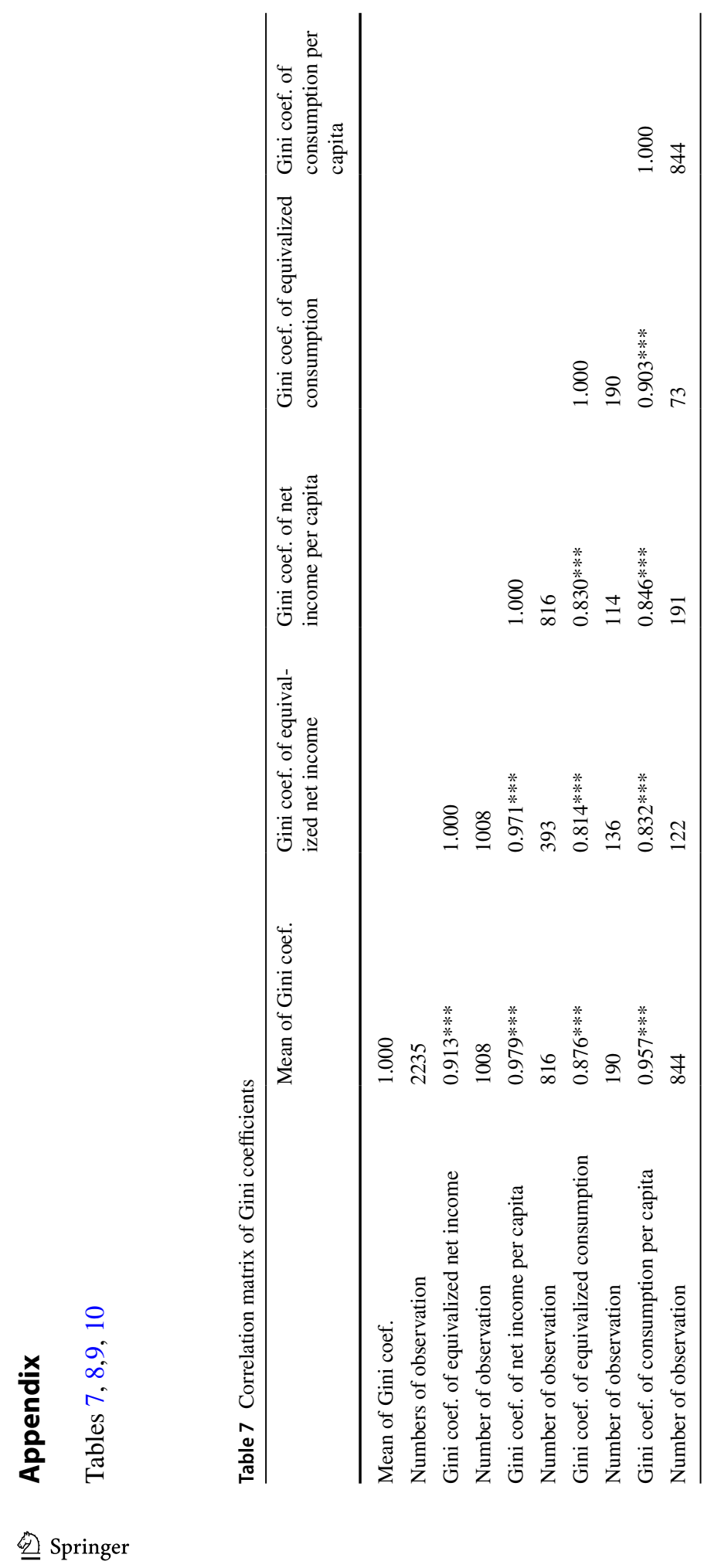




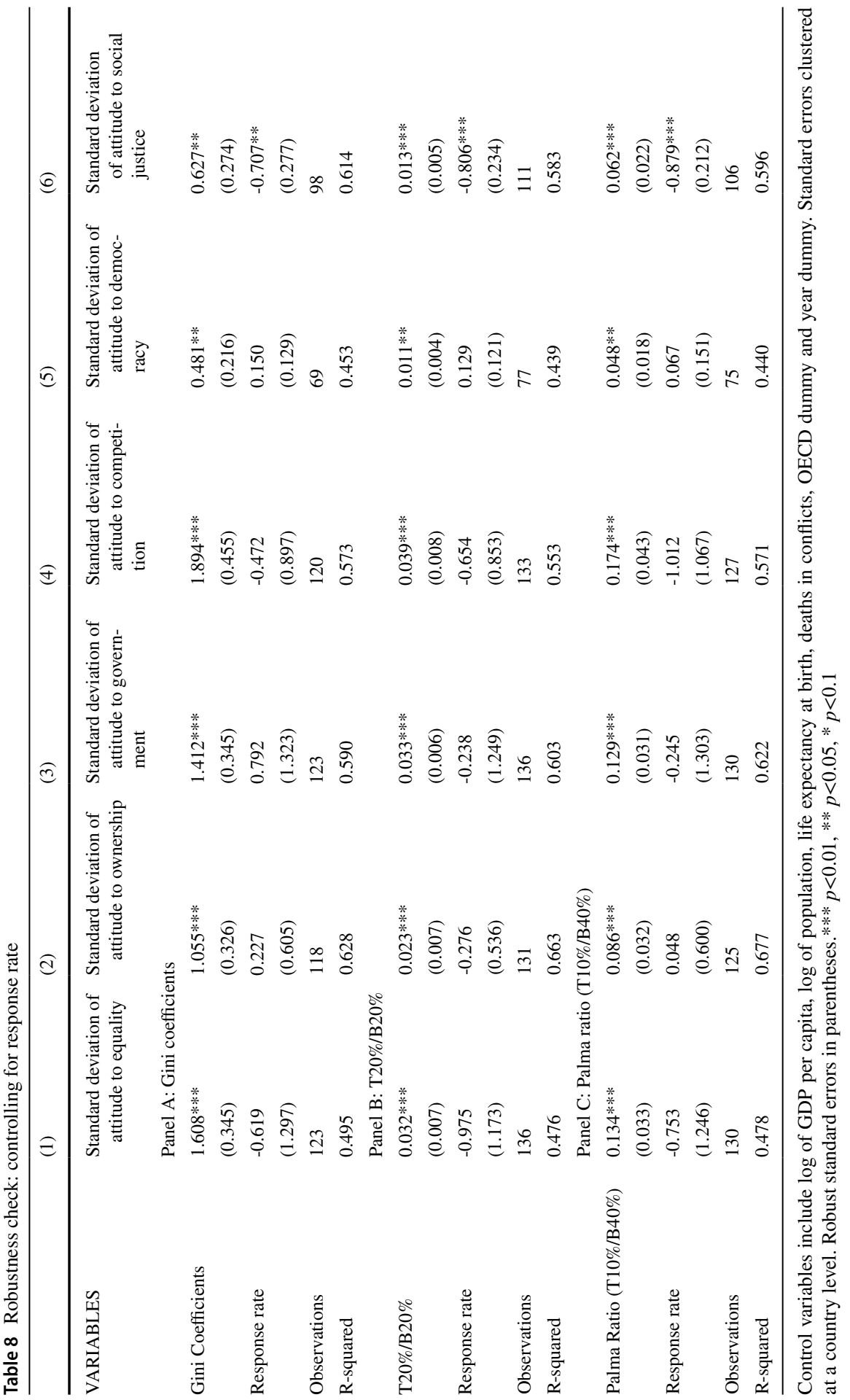




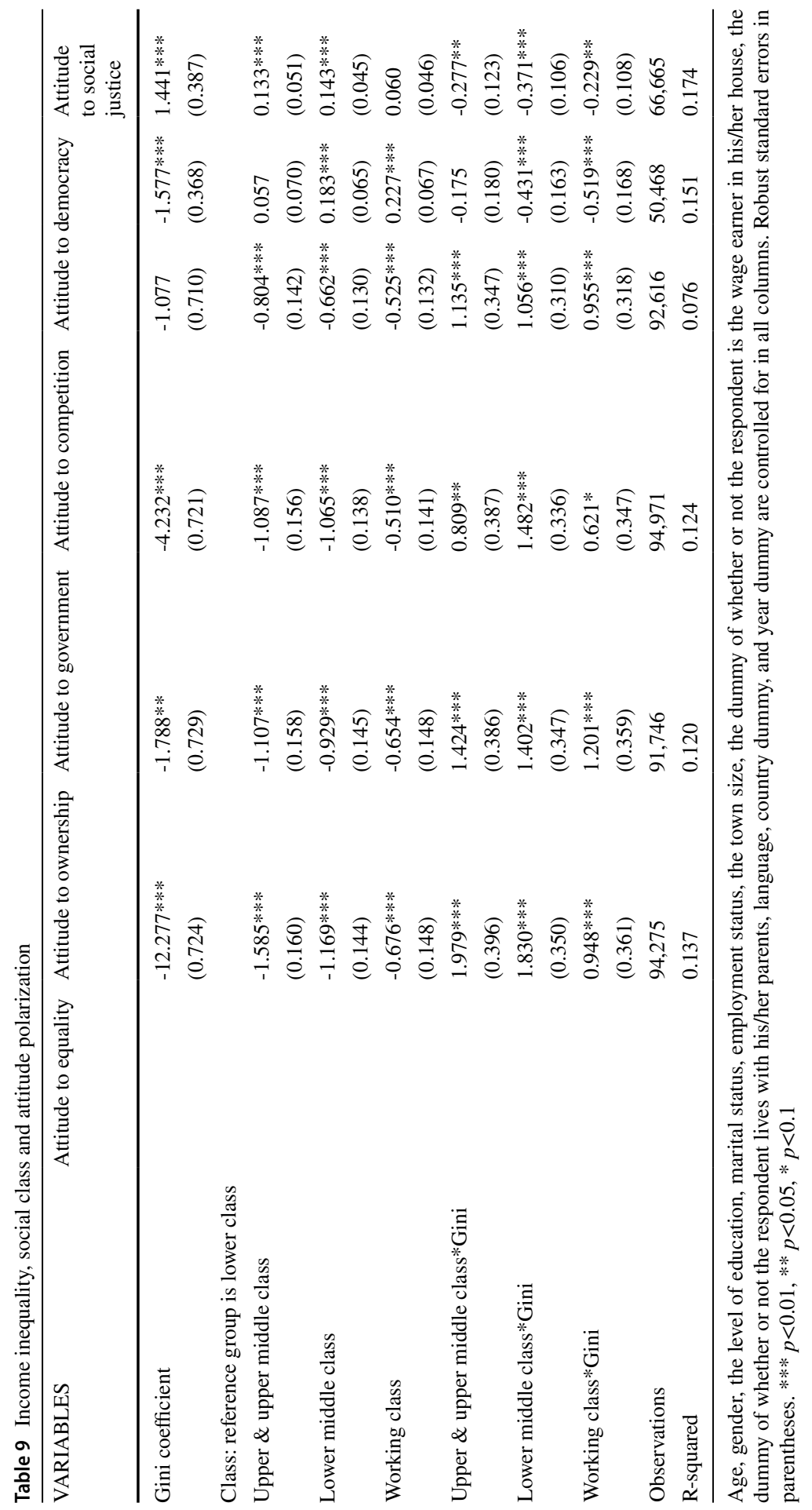




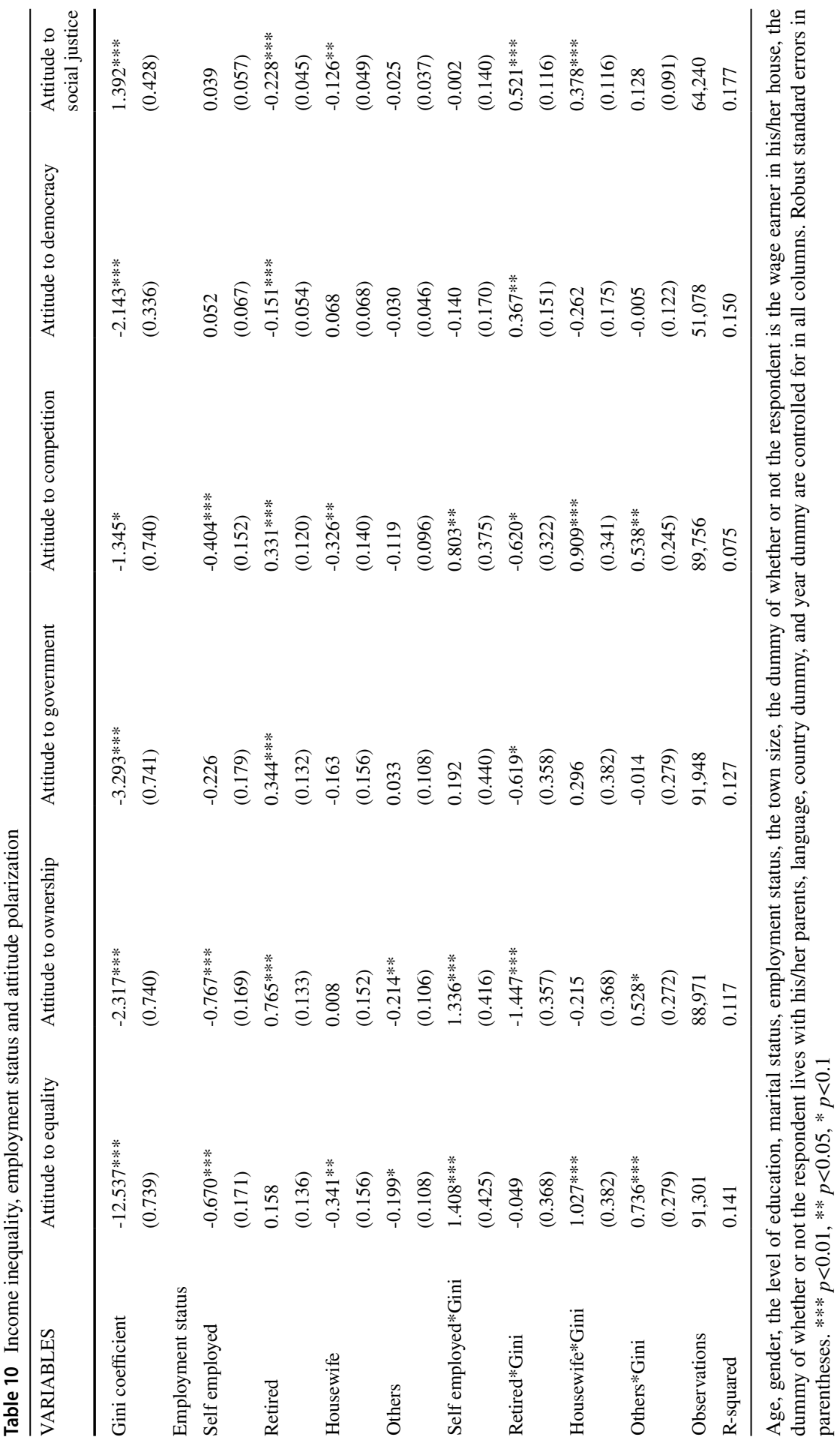


Funding Yanfeng Gu was financially supported by Shanghai Planning Office of Philosophy and Social Sciences [2018BZZ003].

\section{Declaration}

Conflict of Interest No potential competing interest was reported by the authors.

\section{References}

1. Abadie, A. 2006. Poverty, political freedom, and the roots of terrorism. American Economic Review 96: 50-56.

2. Abramowitz, Alan. 2018. The Great Alignment: Race, Party Transformation, and the Rise of Donald Trump. New Haven: Yale University Press.

3. Alesina, A., and R. Perotti. 1996. Income distribution, political instability, and investment. European Economic Review 40 (6): 1203-1228.

4. Algan, Yann, et al. 2017. The European trust crisis and the rise of populism. Brookings Papers on Economic Activity 2017 (2): 309-400.

5. Andersen, Robert, and Josh Curtis. 2012. The polarizing effect of economic inequality on class identification: Evidence from 44 countries. Research in Social Stratification and Mobility 30: 129-141.

6. Autor, David, et al. 2020. Importing political polarization? The electoral consequences of rising trade exposure. American Economic Review 110 (10): 3139-3183.

7. B'o, Dal, et al. 2018. Economic losers and political winners: Sweden's radical right. Unpublished manuscript.

8. Babones, S. 2008. Income Inequality and Population Health: Correlation and Causality. Social Science \& Medicine 66: 1614-1626.

9. Banerjee, A.V., and E. Duflo. 2003. Inequality and growth: What can the data say? Journal of Economic Growth 8: 267-299.

10. Bartels, L.M. 2008. Unequal Democracy: The Political Economy of the New Gilded Age. Russell Sage Foundation, Princeton, NJ: Princeton University Press.

11. Becker, Sascha O., Thiemo Fetzer, and Dennis Novy. 2017. Who voted for Brexit? A comprehensive district-level analysis. Economic Policy 32 (92): 601-650.

12. Bosancianu, C. 2017. A Growing Rift in Values? Income and Educational Inequality and Their Impact on Mass Attitude Polarization. Social Science Quarterly 98 (5): 1587-1602.

13. Burgoon, Brian. 2012. Inequality and anti-globalization backlash by political parties. European Union Politics 14 (3): 408-435.

14. Clinton, Joshua D., Simon Jackman, and Douglas Rivers. 2004. The Statistical Analysis of Roll Call Data. American Political Science Review 98 (02): 355-370.

15. Colantone, Italo, and Piero Stanig. 2018. The trade origins of economic nationalism: Import competition and voting behavior in Western Europe. American Journal of Political Science 62 (4): 936-953.

16. Dettrey, Bryan J., and James E. Campbell. 2013. Has Growing Income Inequality Polarized the American Electorate? Class, Party, and Ideological Polarization. Social Science Quarterly 94 (4): 1062-1083.

17. DiMaggio, Paul, John Evans, and Bethany Bryson. 1996. Have American's Social Attitudes Become More Polarized? American Journal of Sociology 102 (3): 690-755.

18. Dorn, F., Fuest, C., Immel, L. and Neumeier, F. 2020. Economic deprivation and radical voting: Evidence from Germany, ifo Working Paper, No. 336, ifo Institute - Leibniz Institute for Economic Research at the University of Munich, Munich.

19. Duca, J.V., and J.L. Saving. 2016. Income inequality and political polarization: Time series evidence over nine decades. Review of Income and Wealth 62 (3): 445-466.

20. Enamorado, Ted, et al. 2016. Income inequality and violent crime: Evidence from Mexico's drug war. Journal of Development Economics 120 (C): 128-143.

21. Fiorina, Morris P., and Samuel J. Abrams. 2008. Political Polarization in the American Public. The Annual Review of Political Science 11: 563-588. 
22. Foster, James E., and Michael C. Wolfson. 2010. Polarization and the decline of the middle class: Canada and the U.S. The Journal of Economic Inequality 8: 247-273.

23. Funke, M., M. Schularick, and C. Trebesch. 2016. Going to extremes: Politics after financial crises, 1870-2014. European Economic Review 88: 227-260.

24. Garand, J.C. 2010. Income inequality, party polarization, and roll-call voting in the US senate. The Journal of Politics 72 (4): 1109-1128.

25. Grechyna, Daryna. 2016. On the determinants of political polarization. Economics Letters 144: 10-14.

26. Gu, Yanfeng, Xuan Qin, Zhongyuan Wang, Chunman Zhang, and Sujian Guo. 2020. Global Justice Index Report. Chinese Political Science Review 5: 253-331.

27. Gu, Yanfeng, Xuan Qin, Zhongyuan Wang, Chunman Zhang, and Sujian Guo. 2021. Global Justice Index Report 2020. Chinese Political Science Review 6: 322-486.

28. Haughton, Jonathan, and Shahidur R. Khandker. 2009. Handbook on Poverty and Inequality. Washington, DC.: The World Bank.

29. Hibbs, Douglas. 1987. The political economy of industrial democracies. Cambridge, MA: Harvard University Press.

30. Jenkins, S.P. 2015. World income inequality databases: an assessment of WIID and SWIID. Journal of Economic Inequality 13: 629-671.

31. Jesuit, David K., Piotr R. Paradowski, and Vincent A. Mahler. 2009. Electoral support for extreme right-wing parties: A sub-national analysis of Western European elections. Electoral Studies 28 (2): 279-290.

32. Lee, Frances. 2009. Beyond Ideology: Politics, Principles, and Partisanship in the U.S. Senate. University of Chicago Press.

33. Lewis-Beck, M.S., and M. Stegmaier. 2000. Economic determinants of electoral outcomes. Annual Review of Political Science 3 (1): 183-219.

34. Li, Mengyao, and Wu. Zemin. 2021. Power and Poverty in China: Why Some Counties Perform Better in Poverty Alleviation? Journal of Chinese Political Science. https://doi.org/10.1007/ s11366-021-09765-0.

35. Lindqvist, Erik, and Robert Ostling. 2010. Political Polarization and the Size of Government. American Political Science Review 104 (3): 543-565.

36. Liu, Qingping. 2019. Equal Rights Versus Equal Needs: Global Justice or Global Virtues? Fudan Journal of the Humanities and Social Sciences 12: 275-291.

37. Malgouyers, C. 2017. Trade shocks and far-right voting: Evidence from French presidential elections. RSCAS Research Paper, 21.

38. McCarty, N., K.T. Poole, and H. Rosenthal. 2006. Polarized America: The dance of political ideology and unequal riches. Cambridge, MA: MIT Press.

39. Mutz, D.C. 2018. Status threat, not economic hardship, explains the 2016 presidential vote. Proceedings of the National Academy of Sciences 115 (19): E4330-E4339.

40. Persson, T., and G. Tabellini. 1994. Is inequality harmful for growth? American Economic Review 84: 600-621.

41. Piketty, T., and E. Saez. 2014. Inequality in the long run. Science 344: 838-843.

42. Pontusson, Jonas, and David Rueda. 2008. Inequality as a source of political polarization. In Democracy, inequality and representation, ed. Pablo Beramendi and Christopher J. Anderson, 312-353. New York: Russell Sage.

43. Pontusson, Jonas, and David Rueda. 2010. The politics of inequality: Voter mobilization and left parties in advanced industrial states. Comparative Political Studies 43 (6): 675-705.

44. Runciman, W.G. 1966. Relative deprivation and social justice. New York: Penguin.

45. Sitthiyot, Thitithep and Holasut, Kanyarat. 2020. A simple method for measuring inequality. Palgrave Communications 6 (112), online first, doi: 10.1057/s41599-020-0484-6.

46. Stewart, Alexander J., Nolan McCarty, and Joanna J. Bryson. 2020, Polarization under rising inequality and economic decline, Science Advances 6 (50), eabd4201.

47. Stiglitz, J.E. 2012. The Price of Inequality. New York: W. W. Norton \& Company.

48. Voorheis, John and McCarty, Nolan and Shor, Boris. 2015. Unequal Incomes, Ideology and Gridlock: How Rising Inequality Increases Political Polarization. Available at SSRN: https://doi.org/10. 2139/ssrn.2649215.

49. Winkler, Hernan. 2019. The effect of income inequality on political polarization: Evidence from European regions, 2002-2014. Economics \& Politics 31 (2): 137-162. 
50. World Bank. 2018. Poverty and Shared Prosperity 2018: Piecing Together the Poverty Puzzle, 15. Washington, DC: World Bank.

51. World Bank. 2020. Poverty and Shared Prosperity 2020: Reversals of Fortune. Washington, DC: World Bank.

52. Zuo, Cai. 2021. Integrating Devolution with Centralization: A Comparison of Poverty Alleviation Programs in India, Mexico, and China. Journal of Chinese Political Science. https://doi.org/10. 1007/s11366-021-09760-5. 